Contract No. and Disclaimer:

This manuscript has been authored by Savannah River Nuclear Solutions, LLC under Contract No. DE-AC09-08SR22470 with the U.S. Department of Energy. The United States Government retains and the publisher, by accepting this article for publication, acknowledges that the United States Government retains a non-exclusive, paid-up, irrevocable, worldwide license to publish or reproduce the published form of this work, or allow others to do so, for United States Government purposes. 


\title{
THERMAL ANALYSIS FOR ION-EXCHANGE COLUMN SYSTEM
}

\author{
Si Y. Lee* and William D. King \\ Savannah River National Laboratory \\ Savannah River Site \\ Aiken, SC 29808 \\ Phone: *(803) 725-8462; (803) 725-7556 \\ *si.lee@srnl.doe.gov; william02.king@srnl.doe.gov
}

\begin{abstract}
Models have been developed to simulate the thermal characteristics of crystalline silicotitanate ion exchange media fully loaded with radioactive cesium either in a column configuration or distributed within a waste storage tank. This work was conducted to support the design and operation of a waste treatment process focused on treating dissolved, high-sodium salt waste solutions for the removal of specific radionuclides. The ion exchange column will be installed inside a high level waste storage tank at the Savannah River Site. After cesium loading, the ion exchange media may be transferred to the waste tank floor for interim storage. Models were used to predict temperature profiles in these areas of the system where the cesium-loaded media is expected to lead to localized regions of elevated temperature due to radiolytic decay. Normal operating conditions and accident scenarios (including loss of solution flow, inadvertent drainage, and loss of active cooling) were evaluated for the ion exchange column using bounding conditions to establish the design safety basis. The modeling results demonstrate that the baseline design using one central and four outer cooling tubes provides a highly efficient cooling mechanism for reducing the maximum column temperature. In-tank modeling results revealed that an idealized hemispherical mound shape leads to the highest tank floor temperatures. In contrast, even large volumes of CST distributed in a flat layer with a cylindrical shape do not result in significant floor heating.
\end{abstract}

Key words: Thermal Modeling, Cesium Removal, Packed Column, Radioactive Waste Storage Tank, High Level Waste, Crystalline Silicotitanate

\section{INTRODUCTION}

The Small Column Ion Exchange (SCIX) project is designed to accelerate closure of High Level Waste (HLW) tanks at the Savannah River Site (SRS). The SRS tanks are used to store HLW slurries composed of three distinct but mixed phases: sludge (insoluble metal oxides and hydroxides), saltcake (precipitated metal nitrates and carbonates), and supernate (concentrated, aqueous sodium salt solutions). The primary SCIX technology involves an in-tank ion exchange (IX) process to treat supernate and dissolved saltcake waste. Through this process, radioactive cesium from the salt solution is adsorbed onto the ion exchange media (crystalline silicotitanate - CST) [Cherry et al., 2004] which is packed within a flow-through column. The column size for this application is smaller than would normally be used for out-oftank IX processes. A packed column loaded with radioactive cesium generates significant heat from radiolytic decay. If engineering designs cannot handle this thermal load, hot spots may develop locally within the packed bed which could degrade the performance of the ion-exchange media. Performance degradation with regard to cesium removal has been observed between 50 and $80^{\circ} \mathrm{C}$ for CST [Lee and Smith, 2009]. In addition, the waste supernate solution will boil around $130^{\circ} \mathrm{C}$. If the supernate liquid boils away, the dry IX media and residual salts could plug the column and lead to replacement of the entire column module.

One objective of the present work was to compute temperature distributions across a CST-packed column in which the media is immersed in waste supernate or filled with air. Accident scenarios considered included loss of salt solution flow through the bed, complete loss of fluid inside the bed, and loss of coolant system flow. The analysis included evaluations of the effectiveness of the cooling system design under these accident scenarios with full, partial, and no active cooling. The cooling system performance was also evaluated under normal operating conditions involving $5 \mathrm{gpm}$ salt solution flow through the bed.

Another modeling objective of the work was to calculate temperature distributions for a spent CST mound located on the tank floor and a layer of CST dispersed across the tank floor since there was safety concern about tank wall corrosion at the bottom of the mound due to high temperature. The tank floor is a potential interim storage location for the spent CST after removal from the column. The spent CST will be ground prior to transfer to the tank in preparation for vitrification processing of the media in the SRS Defense Waste Processing Facility (DWPF). Thermal evaluations were performed for the ionexchange column and the in-tank regions of the system as shown in Figs. 1 and 2. The column is installed within a large tank in a vertical orientation partially submerged into the tank

The United States Government retains, and by accepting the article for publication, the publisher acknowledges that the United States Government retains, a non-exclusive, paid-up, irrevocable worldwide licence to publish or reproduce the published form of this work, or allow others to do so, for United States Government purposes. 
fluid as shown in Fig. 2. Calculations were conducted in such a manner as to ensure conservative and bounding results for the calculated maximum temperatures.

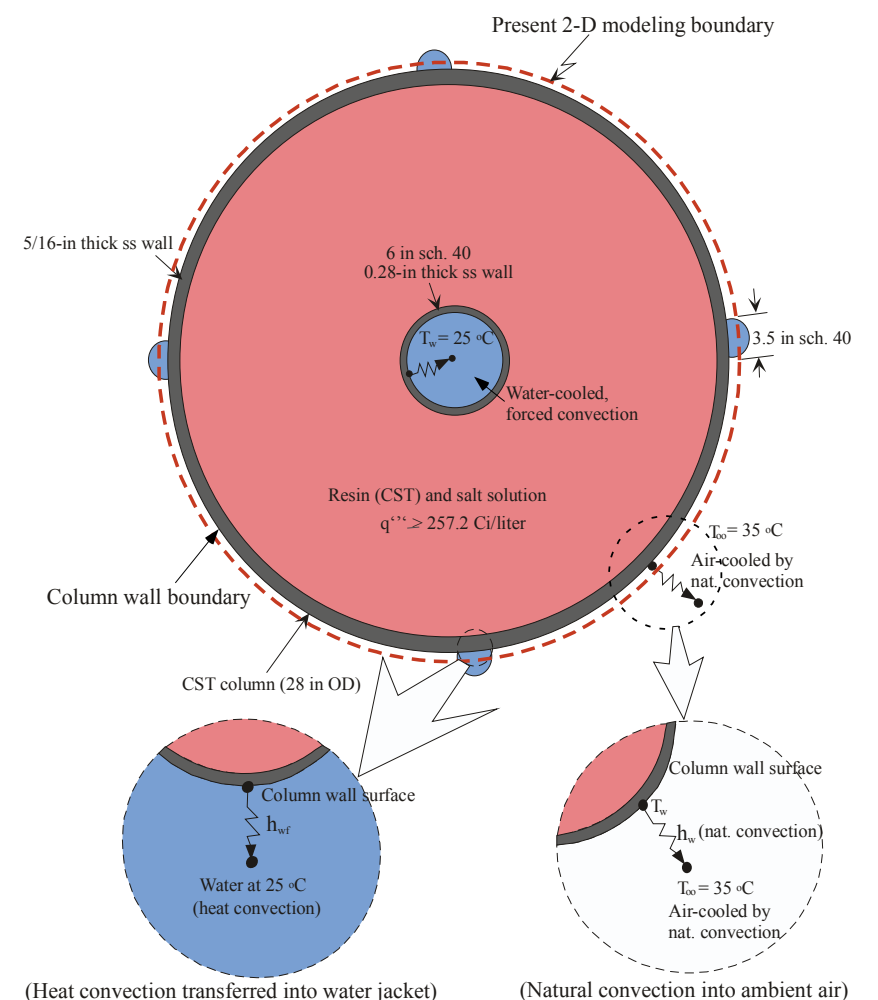

Figure 1. Baseline two-dimensional modeling domain for the ion-exchange column with CST media (considers on radial heat transfer)

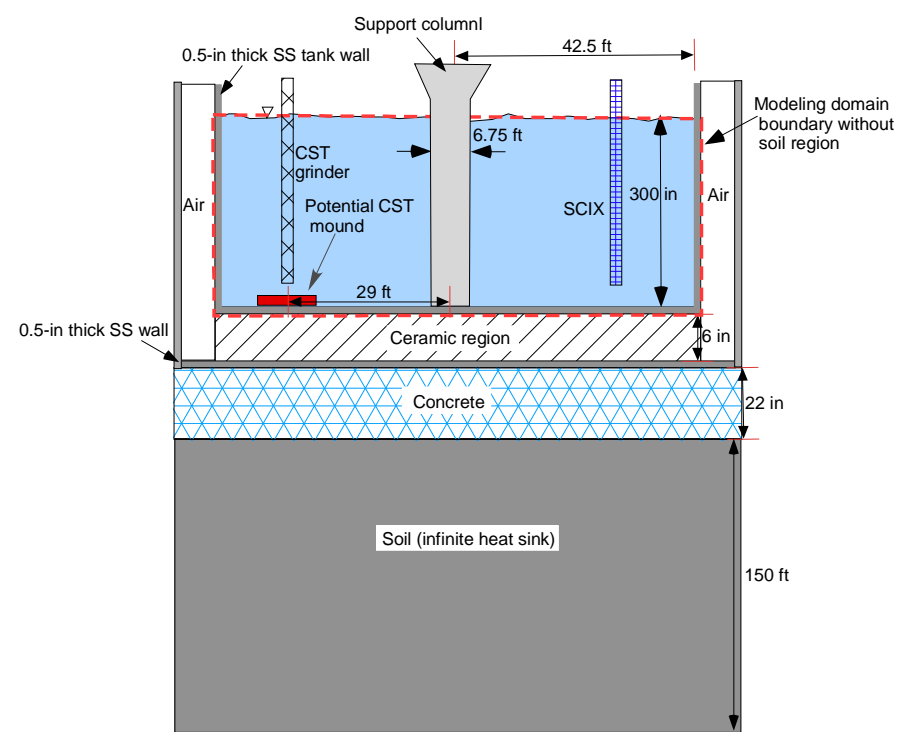

Figure 2. Initial baseline three-dimensional modeling boundary for in-tank calculations (548 vertical cooling tubes inside the tank not shown here)
The thermal modeling evaluations were based on the maximum bounding cesium loading considered possible based on current knowledge regarding CST media and the anticipated salt solution composition. In order to ensure conservative predictions, cesium loading values were assumed to be considerably higher than would be expected under nominal conditions with SRS waste solutions based on loading isotherm model predictions [King et al, 2007]. The baseline design for the CST column was used as depicted in Fig. 1 where a horizontal slice of the column is shown. The column design involves an annular bed geometry with a central cooling tube and four outer cooling tubes. Detailed sensitivity analyses were performed for the column in order to identify key parameters that significantly impact the system thermal characteristics. A safety temperature limit of $130{ }^{\circ} \mathrm{C}$ based on the salt solution boiling point was used as a measure for the evaluation of the incolumn cases, although boiling cannot occur for the air-filled column case where no liquid is present. An operational temperature limit of $55{ }^{\circ} \mathrm{C}$ was also used in order to avoid conditions which might result in performance degradation of the CST media. For in-tank evaluations, the equipment configuration shown in Fig. 2 involving a typical SRS tank was used as the baseline configuration. The location of the heat source region on the tank floor associated with the accumulation of CST material was assumed to be just under the IX media grinder. The shape of the CST heat source was assumed to be cylindrical. Selected alternative configurations involving other geometrical shapes (included a hemi-spherical shape) for the CST mound were also evaluated. In addition, evenly distributed layers of CST media on the tank floor were evaluated to simulate an ideally mixed and settled tank. A tank wall temperature limit criterion of $100^{\circ} \mathrm{C}$ was used for in-tank evaluations based on current SRS tank structural integrity temperature limits [Lee and Smith, 2009]. Sensitivity analysis for the in-tank region was performed for different amounts of CST and combinations of CST with loaded Monosodium Titanate (MST) [Duff et. al. 2004] and sludge materials. MST IX media is currently used for the sorption and removal of actinides and radioactive strontium from the waste solutions [Huff et al., 2011]. The waste tank would also likely contain some sludge (dominated by iron, aluminum, uranium, manganese, and nickel oxides/hydroxides).

\section{MODELING APPROACH AND SOLUTION METHOD}

The SCIX modeling and analysis scope included two main domain areas with separate computational models being used for each domain. One model involved the in-column heat transfer analysis for a two-dimensional, horizontal slice of the ion exchange column containing CST and either salt solution or air. The domain for the other model, referred to as the in-tank model, included the entire waste tank in three-dimensional space with accumulated spent CST materials on the floor. In addition, cooling system performance was evaluated for the in- 
column case under normal solution flow conditions ( 5 gpm feed flow). For these calculations, an overall energy balance for column system was used as a conservative estimate of the maximum solution temperature exiting the column.

The SCIX in-tank cesium-removal system contains two ionexchange column modules and one IX media grinder inside an 85 -ft diameter SRS tank. The in-tank modeling domain including the cylindrically accumulated mound of spent CST is presented in Fig. 2. This figure includes the 150-ft soil region below the tank bottom although some modeling cases do not include it as part of the computational domain. Detailed descriptions for the modeling cases will be provided later. The vertically-oriented column module is designed for cesium removal from HLW salt solutions by down flow processing. The 28-inch diameter column design includes a 6 inch inner cooling tube and four 3.5 inch half-pipe outer cooling tubes. The annulur region of the column is packed with CST ion exchange media which is immersed in salt solution with at least 5 gpm of active solution flow under normal operating conditions. The baseline design includes a 15 foot tall column which contains 450 gallons of CST media. Cooling system evaluations used baseline coolant flowrates of $6.25 \mathrm{gpm}$ for the outer cooling jackets and $12.5 \mathrm{gpm}$ for the inner cooling tube. The supernate is an alkaline, concentrated sodium salt solution (nominally $6 \mathrm{M} \mathrm{Na}^{+}$). Through this process, radioactive cesium from the salt solution is adsorbed onto the ion exchange media. The packed ion exchange column loaded with radioactive cesium $\left(\sim 5 \times 10^{5} \mathrm{Ci}\right)$ generates significant heat from radiolytic decay.

Under normal operating conditions, process fluid flow through the IX column provides adequate heat removal from the system through a coupled conduction and convection heat transfer mechanism. However, in the case of loss of fluid flow or inadvertent solution leakage from the column, there are safety concerns about the thermal response rate of the fullyloaded column and the effectiveness of the column cooling system. If engineering designs cannot handle this thermal load, hot spots may develop locally within the bed which could degrade the performance of the ion-exchange media. The waste supernate solution will also boil around $130{ }^{\circ} \mathrm{C}$. If the columns boiled dry, the dry IX media and sodium salts could foul and plug the column. The baseline design for the column module shown in Fig. 1 was used as the calculation domain. The baseline modeling conditions used for the in-column analysis are provided in Table 1.

A conservative approach was taken for the in-column analysis by assuming that the primary cooling mechanisms inside and outside of the column are conduction and natural convection, respectively, and axial heat removal effects from the column are negligible compared to radial heat transfer. Under stagnant fluid flow conditions inside the packed column, convective heat transfer will reduce the maximum bed temperatures as thermal gradients in the column promote density-driven fluid motions through the bed. In practice, much of the column exterior will be immersed in the supernate solution stored in the waste tank (See Fig. 2) and heat transfer from the column will be significantly increased relative to the case where the primary cooling mechanism is natural convection of air inside the tank. Finally, ignoring end effects adds another level of conservatism to the calculations which are intended to determine the bounding maximum temperatures within the system for the establishment of a design safety basis.

Table 1. Modeling conditions used for the heat transfer analysis of the ion exchange column.

\begin{tabular}{|c|c|}
\hline Models & Conditions \\
\hline Column heat load & $257.22 \mathrm{Ci} /$ liter $\left(1273.24 \mathrm{~W} / \mathrm{m}^{3}\right), 300 \mathrm{Ci} /$ liter* \\
\hline CST material porosity & $24.0 \%$ [Spencer et al., 2000] \\
\hline $\begin{array}{l}\text { Column hydraulic } \\
\text { conditions }\end{array}$ & no flow, or 5 gpm flow* \\
\hline Column media & wet or dry bed* \\
\hline Granular bed conditions & fixed \\
\hline Initial temperature & $35^{\circ} \mathrm{C}$ for entire computational domain \\
\hline Ambient temperature & $35^{\circ} \mathrm{C}\left(55^{\circ} \mathrm{C}\right)^{*}$ \\
\hline $\begin{array}{c}\text { Heat transfer } \\
\text { coefficient at wall, } \\
h_{w}\left(\mathrm{~W} / \mathrm{m}^{2} \mathrm{sec}\right)\end{array}$ & $\begin{array}{l}238 \text { (for 6-in water pipe wall) } \\
620 \text { (for column wall surface attached to } \\
\text { water jacket) [Dittus and Boelter, 1932] } \\
1.5 \text { (typical natural convection at exterior } \\
\text { column walls) [Smith et al., 2008] }\end{array}$ \\
\hline Coolant water flowrate & $\begin{array}{l}6.25 \mathrm{gpm} \text { for side jackets } \\
12.5 \mathrm{gpm} \text { for annular central coolant pipe }\end{array}$ \\
\hline $\begin{array}{l}\text { Coolant water } \\
\text { temperature }\end{array}$ & $\begin{array}{l}\text { no forced circulation or } 25^{\circ} \mathrm{C}\left(35^{\circ} \mathrm{C}\right) * \text { fixed } \\
\text { by forced circulation }\end{array}$ \\
\hline Bed porosity & $43.2 \%$ [Spencer et al., 2000] \\
\hline Column height (ft) & $15(10,25)^{*}$ \\
\hline
\end{tabular}

A radial, transient two-dimensional heat conduction model was developed to assess the thermal performance of the packed CST column using the prototypic geometry. Heat transfer calculations of the CST column were performed for a given boundary condition by using a computational heat transfer approach on a Cartesian x-y grid under a commercial CFD code, Fluent. For the computational domain, about 8,000 mesh nodes for the in-column thermal analysis were established through sensitivity analysis as shown in Fig. 3. Two basic process scenarios were evaluated using the in-column model. One case involves a packed CST bed filled with salt solution, while the other involves a packed CST bed filled with air and no salt solution. The dry column could potentially result from processing accidents such as inadvertent fluid drainage resulting from incorrect valve operations or column overheating and solution boiling.

Spherical CST particles are assumed to be homogeneously packed inside a stainless steel cylinder that is 28 inches in diameter with a 0.5 inch thick wall. Detailed material and thermal properties for the wet and dry CST columns are summarized in Table 2. The CST packed bed porosity was determined to be $43.2 \%$ based on Oak Ridge National Laboratory (ORNL) measurements [Spencer et al., 2000]. The 
void volume fraction of the packed bed has a substantial impact on estimations of the thermal conductivity of a composite mixture. In the ORNL work, the bulk density of the CST column filled with air was determined to be $1,168 \mathrm{~kg} / \mathrm{m}^{3}$ based on a CST material density is $2,056 \mathrm{~kg} / \mathrm{m}^{3}$. Modeling calculations for the in-column analysis involved the following assumptions (unless otherwise indicated) in order to ensure conservative results for the maximum temperatures.

- The column is filled with a fixed, packed bed of CST particles with homogeneous packing.

- The CST bed is immersed in salt solution or air with no active cooling or convective fluid flow through the bed.

- The CST particle and salt solution (or air for the dry bed case) are in local thermal equilibrium so that an average effective thermal conductivity can be assumed for the packed bed.

- The column is suspended in unventilated dry air at $35^{\circ} \mathrm{C}$ rather than salt solution (more likely scenario) within the HLW tank.

- Outside of the column there is no forced convective airflow, so natural convection is the primary heat transfer mechanism from the exterior column wall. In practice, the tank headspace is typically actively ventilated with forced air flow. Radiative cooling contributions at the outer wall surfaces of the column are also considered.

- A typical natural convective heat transfer coefficient $\left(h_{w}\right)$ of $1.5 \mathrm{~W} / \mathrm{m}^{2} \mathrm{~K}$ was used as an external wall boundary condition based on previous analysis [Smith et al., 2008].

- The initial heat source term used of $257 \mathrm{Ci} /$ liter of packed bed is $115 \%$ of the maximum cesium loading of 223 $\mathrm{Ci} /$ liter predicted for the various SRS waste compositions considered for SCIX processing [Lee and Smith, 2009]. Additional calculations were conducted using a source term of $300 \mathrm{Ci} /$ liter which is $135 \%$ of the maximum anticipated cesium loading. The heat source was calculated assuming secular equilibrium involving ${ }^{137} \mathrm{Cs}$ and ${ }^{137 \mathrm{~m}} \mathrm{Ba}$ decay. The heat source is assumed to be uniformly distributed throughout the entire packed column as would be expected for cesium-saturated media. The heat source term of $257 \mathrm{Ci} /$ liter corresponds to 1.273 W/liter.

When the column becomes dry as a result of accidental drainage or solution boiling, the following additional assumptions were used.

- The CST material is completely dry throughout the bed.

- The air-packed column volume remains homogeneously packed and fixed relative to the initial packed configuration.

- Chemical reactions of the dried CST media that could lead to changes in the thermal or physical properties of the packed bed are neglected.

- Air convection inside the column is conservatively neglected and only conductive heat transfer is considered.
- Radiative cooling contributions to the heat transfer at the inner column wall surfaces are neglected.

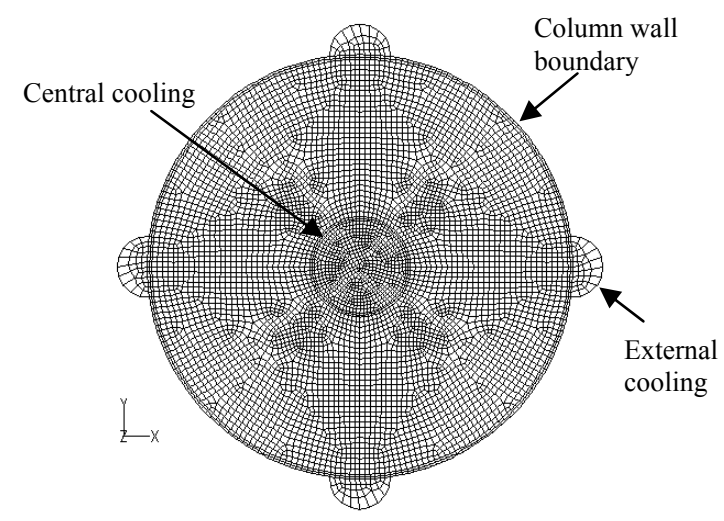

Figure 3. Two-dimensional computational mesh for the incolumn modeling calculations (about 8,000 mesh nodes)

Table 2. Material and thermal properties for heat transfer calculations of the CST, tank, and soil for the in-tank model

\begin{tabular}{|c|c|c|c|}
\hline Material & $\begin{array}{c}\text { Thermal conductivity } \\
(\mathrm{W} / \mathrm{mK})\end{array}$ & $\begin{array}{c}\text { Density } \\
(\mathrm{kg} / \mathrm{m} 3)\end{array}$ & $\begin{array}{c}\text { Specific heat } \\
(\mathrm{J} / \mathrm{kgK})\end{array}$ \\
\hline $\begin{array}{c}\text { Salt Solution } \\
\text { [Smith et al., } \\
\text { 2008] }\end{array}$ & 0.68 & 1232.0 & 3630.0 \\
\hline $\begin{array}{c}\text { CST [Spencer et } \\
\text { al., 2000] }\end{array}$ & 0.1617 & $2056.3^{* *}$ & 1052.3 \\
\hline $\begin{array}{c}\text { CST-Salt Solution } \\
\text { Ground CST-Salt } \\
\text { Solution }\end{array}$ & $0.4125^{\#}$ & $\begin{array}{c}1587.8^{\#} \\
\text { (from eq.7) }\end{array}$ & $\begin{array}{c}2517.3^{\#} \\
\text { (from eq.9) }\end{array}$ \\
\hline CST-Air & $-1.0922 \times 10^{-2}+4.0960 \times 10^{-4} \mathrm{~T}^{*}$ & $1168.0^{* * * *}$ & $1031.9^{* * *}$ \\
\hline Stainless steel & 17.30 & 7800.0 & 486.0 \\
\hline Concrete & 1.5 & 2400 & 750 \\
\hline Ceramic & 18.0 & 3690 & 880 \\
\hline soil & 1.25 & 2000 & 1450 \\
\hline
\end{tabular}

\# based on non-linear empirical correlation of Krupiczka (1967) at $25{ }^{\circ} \mathrm{C}$ considering particle porosities $\left(\varepsilon_{\mathrm{CST} \text {, particle }}=24 \%\right)$ and the volume fractions of air or fluid in the packed beds ( 0.432 for CST bed), giving total bed porosities of 0.57 for CST (total porosity evaluated considering bead and bed porosity.). In case of ground CST for the in-tank modeling analysis, porosity is assumed to be reduced by $50 \%$ due to more compact packing resulting from void filling with smaller particles.

$* \mathrm{~T}$ is absolute temperature in $\mathrm{K}$

** based on material density (not bulk density)

*** based on condition that volume fraction of fluid or air in packed bed is 0.432 at $25^{\circ} \mathrm{C}$ temperature 
Using the modeling domain boundary in Fig. 1 and the computational meshes in Fig 3, the in-column modeling calculations were performed for a range of conditions to estimate maximum bed temperatures in a conservative way along with the additional case involving $5 \mathrm{gpm}$ flow evaluated separately. For each basic case (wet and dry) temperature distributions were calculated with and without active cooling.

For a conservative calculation, a low temperature gradient at the wall boundary layer was used to estimate the natural convection capability for the present geometrical configurations. The heat transfer coefficient $\left(h_{w}\right)$ for natural convective cooling under a turbulent flow regime $\left(\mathrm{Ra}_{f}=G_{L} \mathrm{Pr}_{f}\right.$ $\left.>10^{9}\right)$ is given empirically in terms of non-dimensional numbers [Warner and Arpaci, 1968].

$N u_{L}=\frac{h_{w} L}{k_{w}}=C\left(G r_{L} \operatorname{Pr}_{f}\right)^{m}$ for $G r_{L} P r_{f}<10^{12}$

where $\mathrm{C}$ and $\mathrm{m}$ are the coefficients determined from literature data and $L$ is the characteristic length of the CST column.

For the present geometrical configuration, the coefficients $(\mathrm{C}=0.10$ and $\mathrm{m}=0.333)$ are reported by Warner and Arpaci (1968) based on the experimental data. From eq. (1), the heat transfer coefficient $\left(h_{w}\right)$ is about $1.5 \quad \mathrm{~W} / \mathrm{m}^{2} \mathrm{~K}$ which conservatively corresponds to $N u_{L} \approx 254$ under the present conditions. Heat transfer coefficients $\left(\mathrm{h}_{\mathrm{wf}}\right)$ for forced convective heat transfer mechanisms through the column wall attached to the water jackets and through the inner surface of the coolant pipe at the column center were estimated by the literature correlation [Dittus and Boelter, 1930]. That is,

$N u_{d}=\frac{h_{w f} d_{h}}{k_{w f}}=0.023\left(\operatorname{Re}_{d}\right)^{0.8}\left(\operatorname{Pr}_{w f}\right)^{a}$ for $R \mathrm{e}_{d}>2000$ (2)

Equation (2) is applicable to turbulent flow when the Reynolds number is larger than 2,000 in terms of the hydraulic diameter $\mathrm{d}_{\mathrm{h}}$, and the parameter $a$ in eq. (2) is 0.4 when the fluid is heated. The Reynolds number for the present study is about 7,000 with a 6.25 gpm coolant flow through the 3.5 -in halfmoon coolant tubes, which corresponds to a flow velocity of $0.25 \mathrm{~m} / \mathrm{sec}$. The 6 -in central tube with $12.5 \mathrm{gpm}$ coolant flow is about 5,500 Reynolds number. In the present work, some modeling cases include active engineered cooling systems with a forced convection mechanism as shown in Table 1. Forced convection heat transfer coefficients at the water jackets $\left(h_{w f}\right)$ attached to the exterior of the column wall and at the inner surface of 6 -in central pipe were estimated by eq. (2). From the baseline modeling conditions, the wall heat transfer coefficient governed by a forced convection mechanism was estimated by Eq. (2) as $h_{w f}=238\left(\mathrm{~W} / \mathrm{m}^{2} \mathrm{~K}\right)$ for the wall surface of the central coolant pipe and $h_{w f}=620\left(\mathrm{~W} / \mathrm{m}^{2} \mathrm{~K}\right)$ for the wall of 3.5 -in water jacket. Table 3 shows a range of total heat loads generated by the SCIX column as a function of the column height and the cesium loading. These heat loads were used as the volumetric heat source term q" "for the modeling calculations.
A solution method has been established to calculate steadystate and transient temperature responses of the column system to the heat load q"". The transient calculations were continued until maximum temperatures for the components were reached. In this work, two temperature limits were used for the operation and safety criteria in the thermal evaluation of the SCIX system. An operational temperature limit of $55{ }^{\circ} \mathrm{C}$ was applied to prevent degradation of CST media. The other is used as a safety limit, that is, the solution temperature should be kept below the $130^{\circ} \mathrm{C}$ to avoid solution boiling in the column.

Complete setup of the modeling calculations requires the input parameters such as thermal and material properties of the components, heat source term, and initial boundary conditions along with the established modeling domain. For the heat transfer analysis of the CST column, the energy balance equation is applied to the two-dimensional computation domain as shown in Fig. 1, assuming that the axial heat transfer of the column is negligible. For conservative heat transfer calculations, the heat source was estimated for a fully-loaded and uniformly-distributed bed packed with CST solid material. The initial calculations used $257 \mathrm{Ci} /$ liter for CST, corresponding to 1.273 watts/liter, as volumetric heat source q" as shown in Table 3. The transient model considered temperature-dependent thermal properties to predict transient thermal responses of the fixed bed region in the case of loss of solution flow.

Table 3. Heat source terms for the baseline column shown in Fig. 1.

\begin{tabular}{|c|c|c|c|}
\hline $\begin{array}{c}\text { Column } \\
\text { height } \\
\text { (ft) }\end{array}$ & $\begin{array}{c}\text { Total } \\
\text { column vol. } \\
\text { (liters) }\end{array}$ & $\begin{array}{c}\text { Volumetric heat } \\
\text { load, q,', Ci/liter } \\
\text { [watts/liter] }\end{array}$ & $\begin{array}{c}\text { Total heat sources } \\
\text { generated by column } \\
\text { loading (watts) }\end{array}$ \\
\hline \multirow{2}{*}{10} & \multirow{2}{*}{1154.7} & $257[1.273]^{* *}$ & 1470 \\
\cline { 3 - 4 } & \multirow{2}{*}{15} & $300[1.485]$ & 1715 \\
\hline \multirow{2}{*}{25} & \multirow{2}{*}{2886.6} & $257[1.273]^{* *}$ & 2205 \\
\cline { 3 - 4 } & & $300[1.485]$ & 2572 \\
\hline
\end{tabular}

${ }^{*}$ Conversion factor for Cs-137 decay heat is 0.00495 watts/Ci.

**Baseline loading.

For computational efficiency, an effective thermal conductivity for the composite column region was used. The effective thermal conductivity of the CST bed region was estimated by a literature correlation [Spencer et al., 2000]. The effective thermal conductivity of the bed $\left(k_{b, \text { eff }}\right)$ in Eq. (3) was developed as a function of the bed porosity, $\varepsilon$, in SI units $(\mathrm{W} / \mathrm{mK})$ using the literature experimental data.

$k_{b, \text { eff }}=k_{f}\left(\frac{k_{\text {peff }}}{k_{f}}\right)^{A+B \log \left(\frac{k_{\text {peff }}}{k_{f}}\right)}$

where

$A=0.280-0.757 \log \varepsilon$ and $B=-0.057$. 


$$
k_{\text {peff }}=\varepsilon_{p} k_{f}+\left(1-\varepsilon_{p}\right) k_{p}
$$

In eq. (3), $k_{\text {peff }}$ is the effective thermal conductivity of a CST particle considering particle porosity, $\varepsilon_{p} . k_{f}$ in eq. (3) is the thermal conductivity of the stagnant fluid trapped inside the porous CST particle. Coefficient A is a function of the bed porosity, $\varepsilon$. The thermal conductivity of the CST particle $\left(k_{p}\right)$ is assumed to be constant for computational efficiency.

Effective material properties of the CST column are computed in terms of the bed porosity of the packed column, $\varepsilon$. Effective density, $\rho_{b, e f f}$, and specific heat, $C p_{b, \text { eff, }}$ of the bed column are based on a homogeneous assumption. That is,

$$
\rho_{b, \mathrm{eff}}=\varepsilon \rho_{f}+(1-\varepsilon) \rho_{\text {peff }}
$$

Effective particle density, $\rho_{\text {peff, }}$ is given by the particle porosity, $\varepsilon_{p}$.

$$
\begin{aligned}
& \rho_{\text {peff }}=\varepsilon_{p} \rho_{f}+\left(1-\varepsilon_{p}\right) \rho_{p} \\
& C p_{b, e f f}=\varepsilon C p_{f}+(1-\varepsilon) C p_{\text {peff }}
\end{aligned}
$$

Effective particle specific heat, $C p_{\text {peff, }}$ is given by the particle porosity, $\varepsilon_{p}$.

$$
C p_{\text {peff }}=\varepsilon_{p} C p_{f}+\left(1-\varepsilon_{p}\right) C p_{p}
$$

In eqs. (6) and (7), subscripts $f$ and $p$ refer to the fluid and particle materials within the packed bed, respectively. Computational time can be reduced by modeling a singlematerial region with the effective thermal conductivity instead of modeling a multi-material region composed of two different materials.

Thermal calculations were performed by employing two temperature limits as discussed earlier. Safety criteria limits for the column solution and tank wall temperatures are assumed to be $130{ }^{\circ} \mathrm{C}$ and $100{ }^{\circ} \mathrm{C}$, respectively. These criteria were selected to prevent waste supernate boiling and to avoid structural damage to the tanks. A temperature limit of $55^{\circ} \mathrm{C}$ for the in-tank solution outside the CST column is also assumed for operational control. Using these temperature criteria, various thermal calculations for the in-column module and the in-tank domain were made to quantify key design and operating parameters and evaluate performance with and without engineered cooling systems. For the case of the air-filled column, a series of transient modeling calculations were conducted to determine the maximum bed temperature as a function of time.

This analysis is conservative by nature and gives bounding temperature data. Only conductive heat transfer was considered and it was assumed that the thermal conductivity of the CST material was constant with temperature. Additional transient calculations were conducted under the wet and dry column conditions using a cesium loading of $300 \mathrm{Ci} /$ liter. The modeling results provide quantitative information associated with process heat control and management of the SCIX design.

The energy balance equation defined by the computational grid was solved by an iterative solution method. The detailed solution method was described in the previous work [Lee, 2007]. The overall energy balance should be checked to demonstrate the adequacy of the grid fineness used. This was done by using eq. (10).

$R=-\int_{A_{W}} q_{w}^{\prime \prime} d A+q^{\prime \prime \prime} V_{b}$

The volumetric heat source term, q"', in eq. (10) is given by the code input. For all the cases considered here, the absolute value of the energy residual $(R)$ was maintained at a value less than 0.5 watts. In addition, change of maximum temperatures due to the finer meshes was kept less than $0.5{ }^{\circ} \mathrm{C}$ for gridindependent solution. For instance, the residual results for the wet column model with active central and external cooling systems are shown as function of the grid number in Fig. 4. For the in-column analysis, an optimum grid of about 8,100 cells for the 28-in column was established from the grid sensitivity analysis under the Linux high performance platform.

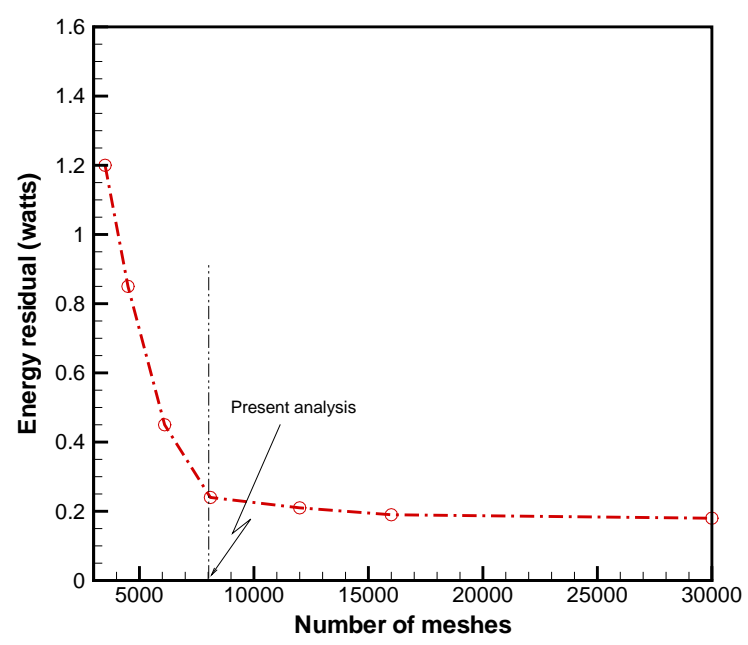

Figure 4. Sensitivity results associated with numerical energy residual showing that approximately 8,100 meshes are sufficient for the present analysis

The baseline configuration for the in-tank thermal analysis is shown in Fig. 2. For the in-tank analysis, there is safety concern about reaching the maximum allowable temperature at the tank wall region under the CST mound since the spent CST material is dropped to the treatment tank floor for interim storage and the tank wall temperature cannot be higher than $100{ }^{\circ} \mathrm{C}$ for preventing the tank wall corrosion.

Three-dimensional in-tank heat transfer models were developed to estimate the maximum temperatures for the liquid and for hot spots on the tank floor under conservative and 
bounding assumptions. Although spent CST volumes was considered for a range of 450 to 6000 gallons over the entire intank domain, the initial thermal calculations considered two geometrical cases involving 6,000 gallons of unground spent CST present on the tank floor as a hemispherical mound or as evenly flat layer with cylindrical mound. A volume of 6,000 gallons was initially selected by the maximum amount of spent CST that might accumulate on the tank floor during processing. The location of the CST mound for Case 1 is just under the grinder region while the flat layer for Case 2 covers the entire bottom tank surface. When the cooling capability is assumed to be uniform over the entire surface area of the 6000-gallon CST mound with its adiabatic bottom surface, heat flow per unit surface area for the flat layer is about 17 times less than that of the hemispherical mound.

Major modeling assumptions for the in-tank calculations are as follows.

- As shown in Fig. 2, the waste tank was considered full (300 inches) of stagnant $6 \mathrm{M} \mathrm{Na}^{+}$supernate with the mixing pumps turned off so that the primary cooling mechanism was natural convection due to buoyancy effects in the tank fluid with the primary heat transfer to the tank cooling system. The tank side wall boundary was cooled by ambient air via a free convection-conduction mechanism coupled with thermal radiation ( 0.3 emissivity wall surface).

- The tank bottom wall boundary was assumed to be adiabatic for initial estimates such that heat transfer through the tank bottom was not allowed. Later heat dissipation across the tank bottom was included for more realistic evaluation.

- Water was maintained as a single phase for simplification and conservatism even if local water temperatures near the CST mound locally exceeded the supernate boiling point of $130^{\circ} \mathrm{C}$.

- Initial temperatures for tank solution, CST, and ambient air were $35^{\circ} \mathrm{C}$.

- 23 equivalent cooling coils corresponding to the total cooling surface area of the entire submerged cooling system (548 tubes, 2-in. diameter) in Tank 41 were evenly distributed across the tank fluid region. The cooling coil wall surface temperature was kept constant at $35^{\circ} \mathrm{C}$.

Figure 5 shows three-dimensional computational meshes for the in-tank modeling domain containing the CST mound inside 300-in tank liquid level. In this case, about $2 \times 10^{6}$ computational nodes were established for the in-tank calculations with cylindrical CST volume of 450 gallon (148-in diameter, 6-in high mound) located at tank floor. Calculations generally involved the determination of steady-state temperatures except for selected cases where transient calculations were conducted. Material and thermal properties for the in-tank calculations are provided in Table 2.

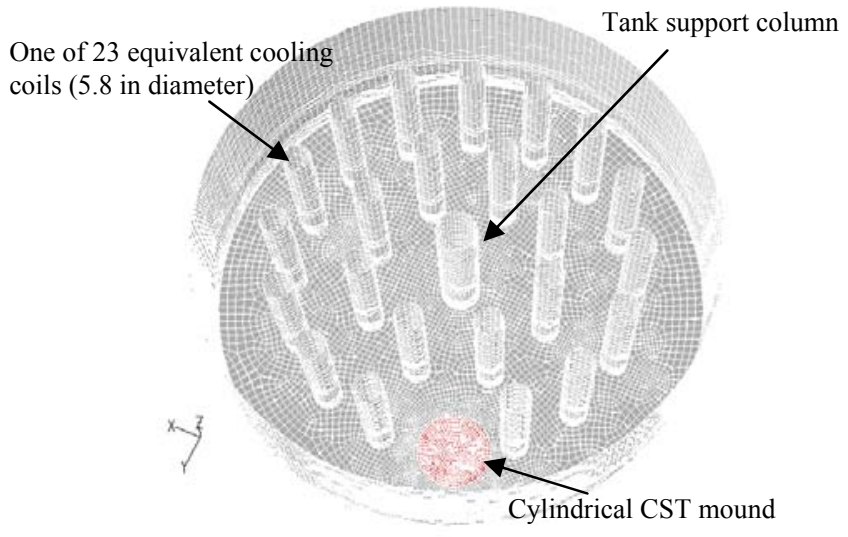

Figure 5. Three-dimensional computational mesh for the intank modeling calculations (about $2 \times 10^{6}$ mesh nodes)

\section{RESULTS AND DISCUSSIONS}

Two computational models have been used to calculate temperature distributions for two distinct modeling domains for the SCIX system. One modeling domain involves the twodimensional in-column heat transfer analysis case shown in Fig. 1, focusing on the solution temperatures inside the ion exchange column. The other domain involves the threedimensional in-tank analysis with CST media accumulated on the tank floor shown in Fig. 2. The in-tank analysis was concerned with the maximum allowable temperature at the tank wall region since the spent CST material is accumulated to the treatment tank floor for interim storage and the tank wall temperature cannot exceed $100{ }^{\circ} \mathrm{C}$ to prevent the wall corrosion.

For the in-column cases involving stagnant liquid, convective heat transfer mechanisms associated with movement of the mobile liquid phase within the column were assumed to be negligible as a conservative estimate of the maximum column temperature. The external wall surfaces of the wet and dry columns were cooled by natural convection coupled with radiation.

For the baseline in-column case, the column was assumed to be cooled by forced convective cooling through the central cooling tube and the four external cooling tubes with natural convection cooling of the remaining column wall portions. Detailed cases for the in-column evaluations are shown in Table 3. A constant ambient temperature of $35{ }^{\circ} \mathrm{C}$ was assumed for all modeling cases. For both in-column and intank modeling, cesium loading on CST was assumed to be 257 $\mathrm{Ci} /$ liter (1.273 watts/liter) based on previous analysis which indicated that this was the highest loading for the anticipated feeds.

The performance model was benchmarked against the theoretical results to verify the computational results against the theoretical results as provided later. The verified model was used for the thermal calculations for the in-column and intank models. The thermal analysis and evaluation were made 
by applying two temperature limits to the modeling domain as safety criteria. The safety criteria for the column and tank wall temperatures are assumed to be 130 and $100{ }^{\circ} \mathrm{C}$, respectively. A temperature limit of $55^{\circ} \mathrm{C}$ for the tank liquid containing the spent CST is also assumed for operational control.

\section{$\underline{\text { Benchmarking Results }}$}

A theoretical approach for steady-state conduction heat transfer of a multi-layered cylinder containing a heat generation source was taken to verify the present computational model under the geometrical and physical conditions shown in Fig. 6 for a simplified CST-packed column without central and external cooling tubes. These evaluations were conducted to benchmark and validate the heat transfer model. The theoretical model was based on an one-dimensional approach. Under steady-state conditions, the energy equation for the CST column with effective thermal conductivity $k_{b, e f f}$ becomes

$k_{b, e f f} \nabla^{2} T+q^{\prime \prime}=0$

For the CST column region with a uniformly distributed heat generation source q", as shown in Fig. 6, eq. (11) becomes

$\frac{d^{2} T}{d r^{2}}+\frac{1}{r} \frac{d T}{d r}+\frac{q^{\prime \prime \prime}}{k_{b, e f f}}=0$

As boundary conditions, the following relations at the center and wall of the column are applied to eq. (12).

$\left.\frac{d T}{d r}\right|_{r=0}=0$

$T(r=R)=T_{S}$

After integrating eq. (12) and applying the boundary conditions, the radial temperature distribution for the CST column region with heat generation source q" ' becomes

$T(r)=T_{s}+\frac{q^{\prime \prime \prime}}{4 k_{b, e f f}}\left(R^{2}-r^{2}\right) \quad(0 \leq r \leq R)$

Equations governing the stainless wall region $(R \leq r \leq(R+d))$ with no heat source $\left(\mathrm{q}^{\prime \prime},=0\right)$ are

$\frac{d^{2} T}{d r^{2}}+\frac{1}{r} \frac{d T}{d r}=0$

Boundary conditions at the wall of the column are

$T(r=(R+d))=T_{w}$

and

$q_{w}^{\prime \prime}=-\left.k_{w} \frac{d T}{d r}\right|_{r=(R+d)}=h_{w}\left(T_{w}-T_{\infty}\right)$ where $\mathrm{d}$ is the stainless steel wall thickness of the CST column, and $k_{w}$ is thermal conductivity of stainless steel wall.

In eq. (18) the wall heat flux $\left(q_{w}^{\prime \prime}\right)$ can be obtained by the energy balance between the heat source and the heat sink when the volumetric heat source q" is spatially uniform in Region-I of Fig. 6. The resulting equation for the wall heat flux is

$q_{w}^{\prime \prime}=q^{\prime \prime \prime}\left(\frac{V_{b}}{A_{w}}\right)=q^{\prime \prime \prime}\left\{\frac{\pi R^{2} L}{2 \pi(R+d) L}\right\}=q^{\prime \prime \prime}\left\{\frac{R^{2}}{2(R+d)}\right\}$

Using eqs. (17), (18), and (19), the radial temperature distribution of the CST wall region with no heat source $\left(q^{\prime \prime}=0\right)$ becomes

$$
\begin{aligned}
T(r) & =T_{w}+\frac{q_{w}^{\prime \prime}(R+d)}{k_{w}} \ln \left(\frac{R+d}{r}\right) \\
& =T_{w}+\frac{q^{\prime \prime \prime} R^{2}}{2 k_{w}} \ln \left(\frac{R+d}{r}\right) \quad(R \leq r \leq(R+d))
\end{aligned}
$$

The surface temperature can be evaluated by eq. (20). That is,

$$
T_{s}=T_{w}+\frac{q^{\prime \prime} R^{2}}{2 k_{w}} \ln \left(\frac{R+d}{R}\right)
$$

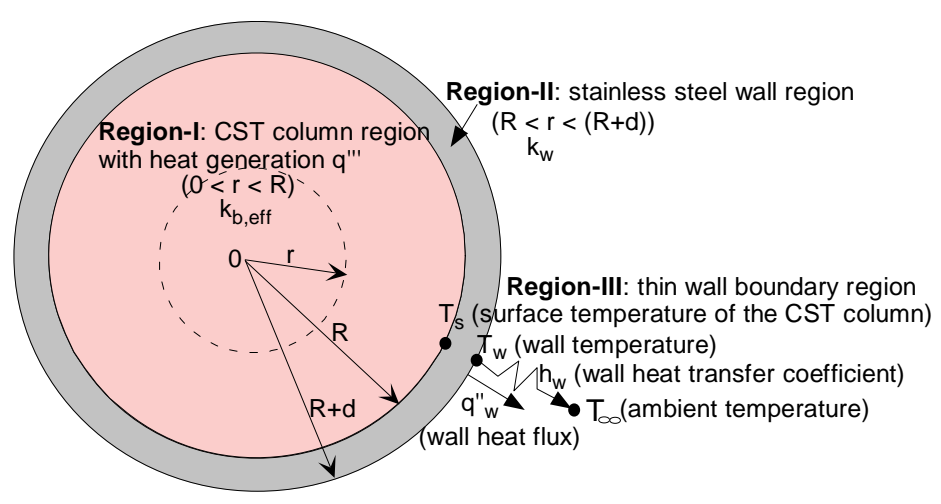

Figure 6. Graphical illustration of the heat transfer model of the Case-I CST column under natural convection cooling.

The wall surface temperature of the CST column $\left(T_{w}\right)$ can be obtained by eqs. (18) and (19) at $r=(R+d)$ in terms of the convection heat transfer coefficient $\left(h_{w}\right)$ at the column wall surface and the ambient temperature $\left(T_{\infty}\right)$ of Region-III shown in Fig. 6.

$$
\begin{aligned}
T_{w} & =T_{\infty}+\frac{q{ }^{\prime \prime}}{h_{w}} \\
& =T_{\infty}+\frac{q^{\prime \prime}}{2 h_{w}}\left(\frac{R^{2}}{R+d}\right)
\end{aligned}
$$


From eqs. (15), (21), and (22), the center temperature of the CST-fluid bed region can be obtained in terms of the natural convection boundary condition and the ambient temperature.

$$
\begin{aligned}
T(r=0)= & T_{\infty}+\left(\frac{q^{\prime \prime \prime} R^{2}}{2}\right)\left\{\frac{1}{h_{w}(R+d)}+\frac{1}{k_{w}} \ln \left(\frac{R+d}{R}\right)\right\} \\
& +\frac{q^{\prime \prime \prime}}{4 k_{b, \text { eff }}} R^{2}
\end{aligned}
$$

The temperature distribution for each region can be nondimensionalized in terms of the column wall temperature difference $\left(T_{w}-T_{\infty}\right)$ and the column radius $(\mathrm{R}+\mathrm{d})$ to examine the impacts of the design parameters on the CST temperature distributions. Non-dimensional parameters shown in Fig. 7 are defined as follows:

$\eta=\frac{r}{(R+d)}$ and $\theta=\left(\frac{T-T_{\infty}}{T_{w}-T_{\infty}}\right)$

Temperature and length scales are non-dimensionalized in terms of the column temperature difference $\left(T_{w}-T_{\infty}\right)$ and the column radius $(\mathrm{R}+\mathrm{d})$ as shown in eq. (24).

For region-I $(0 \leq \eta \leq R /(R+d))$, the non-dimensional temperature distribution can be obtained from eqs. (15), (21), (22), and (24).

$\theta(\eta)=1+\frac{B i}{2} \ln \left(\frac{R+d}{R}\right)+\frac{B i}{4}\left(\frac{k_{w}}{k_{b, e f f}}\right)\left\{1-\left(\frac{R+d}{R}\right)^{2} \eta^{2}\right\}$

The Biot number (Bi) in eq. (25) is defined as the ratio of convection at the wall surface to the conduction through the column wall region. That is

$B i=\frac{h_{w} D}{k_{w}}=\frac{2(R+d) h_{w}}{k_{w}}$

Thus, the Biot number compares the relative magnitudes of surface convection and internal conduction resistance to heat transfer. A very low value for the Biot number means that internal conduction resistance is negligible in comparison with surface convection resistance. This in turn implies that the temperature will be nearly uniform throughout the conduction media.

The non-dimensional temperature distribution for the region-II $(R /(R+d) \leq \eta \leq 1)$ can be obtained from eqs. (20) and (24).

$\theta(\eta)=1-\frac{B i}{2} \ln \eta$

From eq. (25) the maximum temperature of the CST column with a thin wall thickness under steady-state condition becomes $\theta_{\max } \approx 1+\frac{B i}{4}\left(\frac{k_{w}}{k_{b, e f f}}\right)$

Thus, the non-dimensional temperature distributions inside the CST column and wall regions can be computed, and they can be compared with the steady-state numerical results to verify the model predictions. In this case, the numerical solution was obtained by solving the transient governing equations with a sequence of time steps until a steady-state solution is reached. Eq. (28) shows that the maximum temperature gradient is closely related to the wall Biot number and the ratio of thermal conductivity for the column wall region to the effective thermal conductivity of the composite CST column. For a given geometry and wall cooling conditions, the effective thermal conductivity is found to be the key parameter to control the maximum temperature difference between the column center and its wall.

Temperature boundary conditions are provided at the inner and outer wall boundaries of the 28-in column with a volumetric heat source q" " under the same governing equation as the cylindrical geometry, eq. (13). The resulting equation for the temperature distribution $T(r)$ at a radial position $r$ from the column center becomes

$$
\begin{aligned}
T(r)= & T_{w i}-\frac{q^{\prime \prime \prime}\left(r^{2}-R_{i}{ }^{2}\right)}{4 k_{b, \text { eff }}} \\
& +\left[\frac{q^{\prime \prime \prime}}{4 k_{b, \text { eff }}}\left(R_{o}{ }^{2}-R_{i}{ }^{2}\right)-\left(T_{w i}-T_{w o}\right)\right]\left(\frac{\ln \left(r / R_{i}\right)}{\ln \left(R_{o} / R_{i}\right)}\right)
\end{aligned}
$$

In eq. (29) the parameters $R_{i}$ and $R_{o}$ the inner and outer radii, and $T_{w i}$ and $T_{w o}$ are the inner and outer wall temperatures, respectively. In this case, the stainless steel wall regions at the inner and outer edges of the column are not considered for the simplified calculations.

The theoretical temperature distributions were compared with the modeling results for the 28 -in column with a 300 $\mathrm{Ci} /$ liter cesium loading, which corresponds to $1.485 \mathrm{~W} /$ liter. In this case, the stainless steel wall regions at the inner and outer edges of the column are not considered for the simplified calculations. The validated results are shown in Fig. 7, where the model predictions and theoretical results show excellent agreement with the theoretical results to within about $0.01 \%$. 

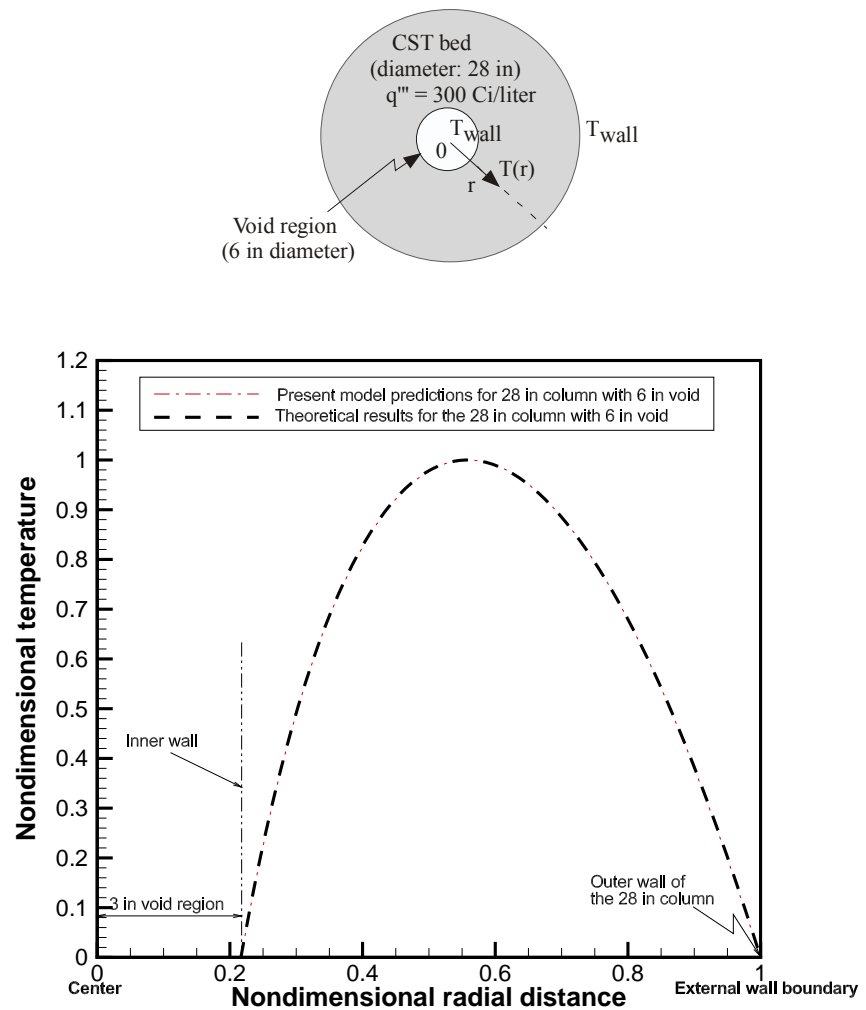

Figure 7. Comparison of steady state results between the numerical computations and theoretical results for the annulartype column with $300 \mathrm{Ci} /$ liter heat load for model benchmarking.

In-Column Thermal Modeling Results

For computational modeling purposes, a conservative approach was taken by assuming that the primary cooling mechanisms inside and outside of the column were conduction and natural convection, respectively. Two-dimensional modeling calculations were conducted with the assumption that axial heat removal (end effects) from the column was negligible relative to radial heat transfer.

For the in-column thermal analysis of the 28-in CST column, $100 \%$ cesium loading, one central cooling and four active external tubes, and $35{ }^{\circ} \mathrm{C}$ ambient temperature were considered to be the baseline conditions. Table 4 shows calculated steady-state maximum temperatures for a range of column conditions with the liquid-filled column. The results indicate that when both the internal and external engineered cooling systems are active and the CST bed is filled with stagnant liquid, the maximum temperature will reach about 63 ${ }^{\circ} \mathrm{C}$. This temperature exceeds the operational control limit of $55{ }^{\circ} \mathrm{C}$ imposed to protect the IX media from chemical degradation and emphasizes the importance of continual fluid flow through the column when the CST is saturated with cesium. With an inactive central cooling and four active external cooling tubes, the peak temperature for the stagnant liquid case is about $114^{\circ} \mathrm{C}$.
When only the central cooling system is active, the peak temperature is near $80{ }^{\circ} \mathrm{C}$. When both of the engineered cooling systems are lost, the column temperature increases to about $156{ }^{\circ} \mathrm{C}$ as shown in Table 4. This temperature would not be observed in practice for the wet column until complete supernate volatilization occurs as a result of boiling at a temperature near $130{ }^{\circ} \mathrm{C}$. Radial, steady-state temperature distributions for the stagnant flow cases are compared in Fig. 8. The location of the maximum temperature within the bed varies depending upon whether the cooling system is active. The maximum is located at the center of the column when the central cooling system is inactive and between the inner and outer walls when the central cooling system is active. The central cooling tube is particularly effective at cooling the column and results in a decrease in the maximum temperature of $76^{\circ} \mathrm{C}$ relative to the case with no active cooling.

With $5 \mathrm{gpm}$ solution flow through the cesium-saturated column and no active cooling, the temperature increases only by 1 to $2{ }^{\circ} \mathrm{C}$ across the column length, depending on the height as shown in Table 4. Fluid flow through the column provides adequate heat removal from the column even without active cooling.

Transient calculational results (not shown) reveal that with no active cooling the maximum temperature for the stagnant, wet column increases to above $75{ }^{\circ} \mathrm{C}$ within two days after cooling system loss. The steady-state boiling temperature of $130{ }^{\circ} \mathrm{C}$ is reached in about 6 days. Calculation results beyond the supernate boiling temperature are meaningless. In contrast, with active cooling (internal and external pipes) the maximum temperature of the stagnant, wet column approaches $60{ }^{\circ} \mathrm{C}$ within 48 hours and the maximum steady-state temperature is only $63{ }^{\circ} \mathrm{C}$, as discussed above.

Table 4. Steady-state maximum column temperatures for various conditions for the wet column

\begin{tabular}{|c|c|c|c|c|}
\hline $\begin{array}{c}\text { Column } \\
\text { Hydraulic } \\
\text { conditions }\end{array}$ & $\begin{array}{c}\text { Central } \\
\text { cooling } \\
\text { system }\end{array}$ & $\begin{array}{c}\text { External } \\
\text { cooling } \\
\text { system }\end{array}$ & $\begin{array}{c}100 \% \text { CST } \\
\text { loading } \\
(\text { Curie/liter })\end{array}$ & $\begin{array}{c}\text { Max. column } \\
\text { temperature } \\
\left({ }^{\circ} \mathrm{C}\right)\end{array}$ \\
\hline \multirow{2}{*}{$\begin{array}{l}5 \mathrm{gpm} \\
\text { flow* }\end{array}$} & Inactive & Inactive & 257 & $36.1(10 \mathrm{ft})^{* *}$ \\
\cline { 2 - 5 } & Inactive & Inactive & 257 & $36.7(15 \mathrm{ft})^{* *}$ \\
\cline { 2 - 5 } & Inactive & Inactive & 257 & $37.8(25 \mathrm{ft})^{* *}$ \\
\hline Stagnant & Active & Active & 257 & 62.7 \\
\hline Stagnant & Active & Inactive & 257 & 80.2 \\
\hline Stagnant & Inactive & Active & 257 & 114.1 \\
\hline Stagnant & Inactive & Inactive & 257 & 156 \\
\hline
\end{tabular}

* based on $35^{\circ} \mathrm{C}$ inlet solution temperature

** Column height

In the case of inadvertent solution leakage from the CST column or complete liquid evaporation due to insufficient cooling, there are safety concerns about the transient thermal response rate of the fully-loaded column and the effectiveness 
of the cooling system at maintaining the temperature of the dry column. Transient calculational results for the dry column are compared for two different thermal loadings in Fig. 9. With a dry column containing a cesium loading of $257 \mathrm{Ci} /$ liter at an initial temperature of $35^{\circ} \mathrm{C}$ and with active engineered cooling, a steady-state maximum temperature of $122{ }^{\circ} \mathrm{C}$ is reached in about 3 days. When the baseline thermal loading of 257 $\mathrm{Ci} /$ liter is increased by about $17 \%(300 \mathrm{Ci} /$ liter $)$ for the sensitivity analysis, the modeling results show that the maximum column temperature increases by about $12 \%$. It is noted that the transient thermal response time of the dry column is more rapid than that of the wet column, as expected.

When both of the internal and external cooling systems are active in case of complete loss of the column solution, the column temperature reaches up to $122{ }^{\circ} \mathrm{C}$. If both of the cooling systems are not active under the dry column conditions, the column temperature reaches $130^{\circ} \mathrm{C}$ in about 2 days. In the event that liquid is lost from the column during processing, a potential operational response is to pump air through the column at a rate of 80 cubic feet per minute. For the case where forced air flow through the dry bed is used to cool the column, the results show that air flow through the bed has a large impact on the maximum bed temperature. The maximum bed temperature is estimated to be less than $100{ }^{\circ} \mathrm{C}$ with air cooling.

Sensitivity analysis was performed for different operating conditions for the wet, stagnant column with active cooling. When the column heat load was increased by about $17 \%$ to 300 $\mathrm{Ci} /$ liter, the maximum column temperature increased by about $14{ }^{\circ} \mathrm{C}$. Increasing the ambient temperature from 35 to $55{ }^{\circ} \mathrm{C}$ resulted in small increases in the maximum column temperature of $<4{ }^{\circ} \mathrm{C}$. Maximum column temperatures were also estimated for different coolant water temperatures. The calculational results show that when the coolant temperature increases by 10 ${ }^{\circ} \mathrm{C}$, the maximum column temperature changes by about $6{ }^{\circ} \mathrm{C}$. Increasing the baseline ambient temperature from $35^{\circ} \mathrm{C}$ to 55 ${ }^{\circ} \mathrm{C}$ for the case with no active cooling, results in a maximum column temperature increase of only about $8{ }^{\circ} \mathrm{C}$.

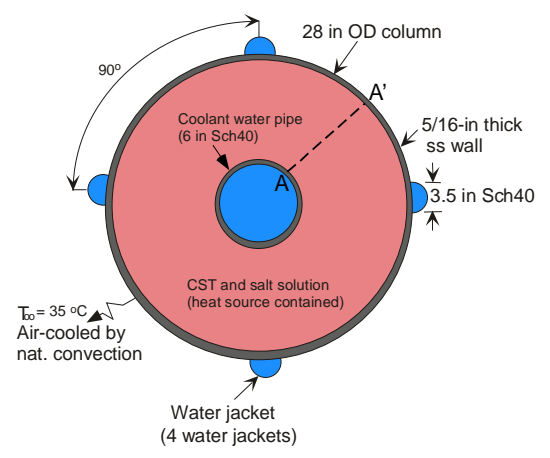

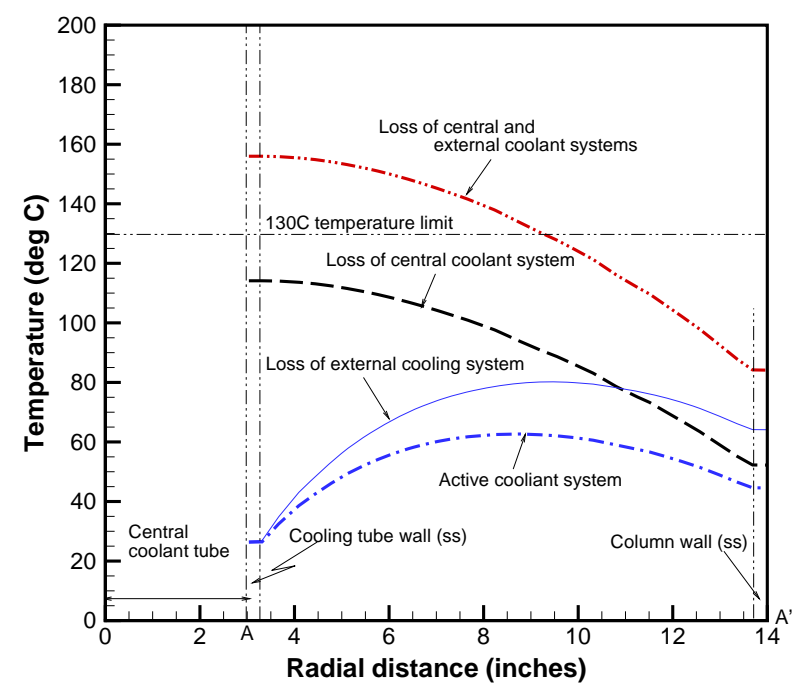

Figure 8. Steady-state column temperature profiles along the radial line A-A' for stagnant wet CST media with active and inactive coolant systems $(257 \mathrm{Ci} /$ liter $)$

\section{In-Tank Thermal Modeling Results}

The two initial cases were considered for the in-tank model involving a hemispherical mound and a pancake layer of unground CST media on the tank floor. These two geometries represent the media distribution extremes, with the hemispherical mound being the worst distribution and the layer being the idealized and best distribution. When the cooling capability is assumed to be uniform over the entire surface area of the 6000-gallon CST mound with an adiabatic bottom surface, heat flux for the flat layer (Case 2) is 55 watts $/ \mathrm{m}^{2}$, which is about 17 times less than that of the hemispherical mound (Case 1) as compared. This indicates that the hemispherical mound shape provides a conservative estimate of the maximum temperature. 


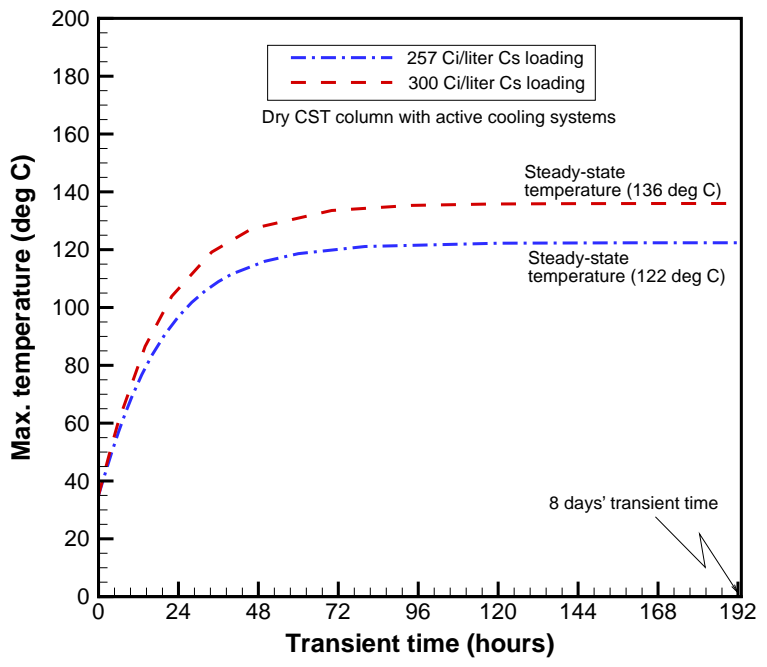

Figure 9. Transient modeling results for the maximum column temperatures following inadvertent loss of process fluid (dry column case) with active internal and external cooling systems ( 257 vs. $300 \mathrm{Ci} /$ liter)

For these initial calculations of Case 1, it was assumed the bottom tank surface was adiabatic as a conservative estimate. The results show that the maximum surface temperature of the hemispherical mound reaches about $100{ }^{\circ} \mathrm{C}$ after 2.5 days, which is the wall temperature limit. Despite this limitation, the results indicate that a 6,000 gallon hemispherical mound of spent CST would cause significant problems with regard to tank temperature control. The transient results at 50 hours' transient time show that the maximum mound surface temperature and the maximum upward fluid velocity driven by buoyancy effects are about $61{ }^{\circ} \mathrm{C}$ and 0.6 inches/sec, respectively.

As discussed earlier, the cooling surface area per unit volume for the flat layer (Case 2) was found to be about 17 times larger than that of hemispherical mound. The steadystate results for flow patterns and temperature distributions for Case 2 show that the maximum tank wall surface temperature reaches about $40^{\circ} \mathrm{C}$ for a dispersed 6000 gallon CST layer with a height of 1.7 -in. In this case the maximum wall surface temperature is far less than the $100{ }^{\circ} \mathrm{C}$ tank temperature limit. This result emphasizes the dramatic impact that effective mixing and dispersion of the spent CST have on the maximum system temperatures. The modeling results for Case 1 indicate that the bottom surface temperature reaches the $100{ }^{\circ} \mathrm{C}$ wall temperature limit after 62 hours and the local fluid temperature reaches the $55{ }^{\circ} \mathrm{C}$ fluid temperature after 83 hours. The calculated Case 1 steady-state temperature of $\sim 1800{ }^{\circ} \mathrm{C}$ is not meaningful or expected because supernate boiling will limit the solution temperature to near $130{ }^{\circ} \mathrm{C}$. The maximum wall temperature for the 6000-gallon flat layer (Case 2) never reaches either temperature limit.
Additional transient modeling calculations were conducted for the hemispherical mound using lower total spent unground CST volumes of 900 and 450 gallons. When the bottom surface of the hemispherical CST mound is assumed to be adiabatic, the $100{ }^{\circ} \mathrm{C}$ wall temperature limit is reached in about 3 days for all cases. A hemispherical mound is likely the worst geometrical shape possible because it involves the smallest ratio of cooling surface area to mound volume. A hemispherical shape is also an idealized shape that might be expected to form from the transport of the CST material to the tank floor. A flatter geometrical shape is probably more likely to be observed. Therefore, other geometrical shapes with larger aspect ratios were considered for in-tank modeling. Specifically, cylindrical shapes with various aspect ratios were evaluated. The cylindrical shape may be more representative of the mound shape formed on the tank floor, although the actual shape will likely be between the various idealized geometries considered.

For the in-tank evaluations, the modeling approach changed as the work progressed based on the results. Initial modeling efforts involved an adiabatic tank floor with no heat transfer into the soil region and unground CST media with a loading of $257 \mathrm{Ci} /$ liter. Due to the high temperatures observed for various modeling cases assuming an adiabatic floor, a new modeling domain was developed which included the soil region below the tank. The 0.5-in thick carbon steel tank bottom wall with multiple lower layers of ceramic and concrete were expected to provide significant heat transfer to the soil region which behaves as in infinite heat sink. Floor heat transfer was also expected to significantly impact the results because this heat transfer mechanism is operative in the exact location of interest as far as the maximum tank temperatures are concerned. Based on previous work [Lee et al., 2011], a 150-foot deep soil region below the tank bottom was expected to provide sufficient depth and heat transfer volume to reach thermal equilibrium at an assumed soil temperature of $20^{\circ} \mathrm{C}$. A schematic of the modified calculation domain including the various known material layers and a 150 foot soil region below the tank is shown along with results in Table 5.

Subsequent analysis with the new model revealed that a significant amount of heat transfer was expected through the floor, which impacted the calculated maximum floor temperatures. When heat transfer across the tank floor is allowed, significantly reduced maximum floor temperatures are observed. A quantitative comparison of maximum tank bottom surface temperatures is provided in Table 5 between the cases with and without floor heat transfer for three different cylindrical CST mound heights. With the floor heat transfer mechanism included, the wall temperature limit of $100{ }^{\circ} \mathrm{C}$ is not exceeded even for a 12 inch high cylindrical mound (900 gallon volume).

As discussed above, it is expected that the total volume has little impact on the maximum tank bottom temperature 
and the key parameter is the height of the mound. Therefore, somewhat larger mound volumes of this same height would also be expected to result in acceptable maximum temperatures. Figure 10 shows a comparison of vertical temperature profiles between the two models with and without heat transfer through the tank bottom for a 12in high cylindrical mound located on the tank floor. This result graphically demonstrates the dramatic impact of floor heat transfer on the maximum wall temperature. It is also noted that when the heat transfer across the tank bottom is considered, the location of the maximum temperature within the mound changes from near the bottom of the mound to the center of the mound.

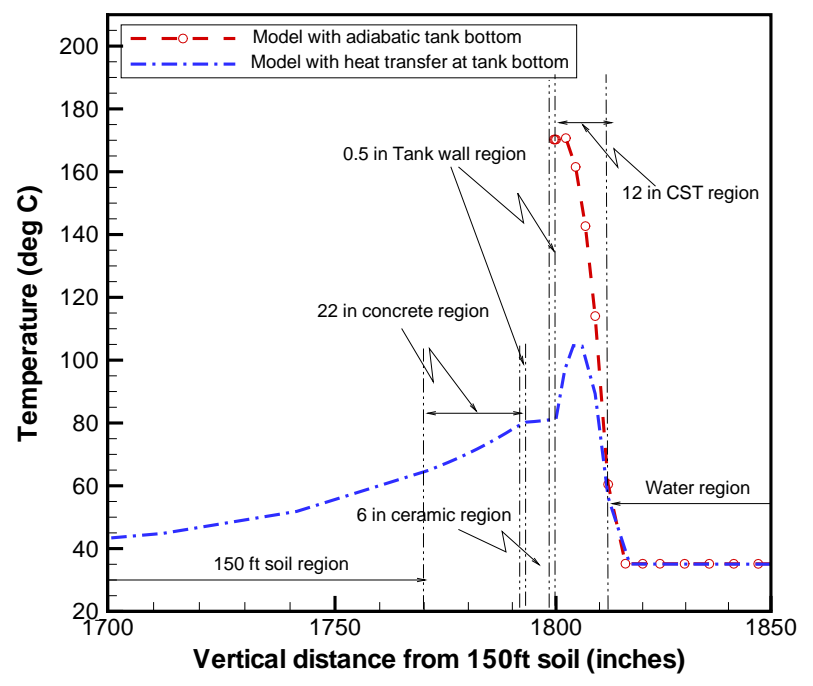

Figure 10. Comparison of temperatures between the models with and without heat transfer through the tank bottom for 12-in cylindrical pancake mound (unground CST)

Table 5. Quantitative comparison* of maximum tank bottom surface temperatures with and without heat transfer for different cylindrical, unground CST mound heights (74 inches in radius)

\begin{tabular}{|c|c|c|}
\hline $\begin{array}{c}\text { Volume of the CST } \\
\text { mound at tank floor }\end{array}$ & $\begin{array}{c}\text { No heat transfer at } \\
\text { tank bottom (Case A) }\end{array}$ & $\begin{array}{c}\text { Heat transfer at tank } \\
\text { bottom (Case B) }\end{array}$ \\
\hline $\begin{array}{c}\text { 12-in high cylindrical } \\
\text { (900 gallons) }\end{array}$ & $170.3^{\circ} \mathrm{C}$ & $81.2^{\circ} \mathrm{C}$ \\
\hline $\begin{array}{c}\text { 9-in high cylindrical } \\
\text { (675 gallons) }\end{array}$ & $136.8^{\circ} \mathrm{C}$ & $68.8^{\circ} \mathrm{C}$ \\
\hline $\begin{array}{c}\text { 6-in high cylindrical } \\
\text { (450 gallons) }\end{array}$ & $81.2^{\circ} \mathrm{C}$ & $54.8^{\circ} \mathrm{C}$ \\
\hline
\end{tabular}

* Based on unground CST loading (257 Ci/liter)

\section{CONCLUSION}

Two separate models have been developed to simulate the thermal characteristics of Crystalline Silicotitanate (CST) ion exchange media fully loaded with radioactive cesium in a column configuration and distributed within a waste storage tank. The models were benchmarked and verified against the theoretical results. Temperature distributions and maximum temperatures across the column and within the mounds were calculated with a focus on process upset conditions.

The main results are summarized as follows:

- With $5 \mathrm{gpm}$ supernate flow through the column and without active engineered cooling the maximum column temperature should be below $40{ }^{\circ} \mathrm{C}$.

- For a CST column filled with stagnant supernate with active engineered cooling, the peak temperature for the fully-loaded wet column is about $65{ }^{\circ} \mathrm{C}$, which is well below the supernate boiling point. This maximum temperature is marginally acceptable with regard to the chemical and physical stability of the CST media.

- For the air-filled column case with active engineered cooling, the maximum temperature is expected to be below $140{ }^{\circ} \mathrm{C}$.

- The column temperature exceeds $100{ }^{\circ} \mathrm{C}$ within 24 hours for the air-filled column with or without active engineered cooling.

- The impact of the central cooling tube is very large under wet and dry column conditions since the cooling region is located at the hottest spot in the column.

- In-tank CST modeling results revealed that a hemispherical shape is the worst case mound geometry and leads to the highest tank floor temperatures. In contrast, even large volumes of CST distributed in a flat layer do not result in significant floor heating.

\section{NOMENCLATURE}

A Coefficient

$\mathrm{A}_{\mathrm{w}} \quad$ Wall area $\left(\mathrm{m}^{2}\right)$

B Coefficient

Bi Biot number $(=\mathrm{hD} / \mathrm{k})$

C Coefficient

$\mathrm{Ci} \quad$ Curie $\left(=3.7 \times 10^{10}\right.$ disintegrations $\left./ \mathrm{sec}\right)$

$\mathrm{Cp} \quad$ Specific heat

d Column wall thickness in Fig. 5

D Column outer diameter in Fig. 5

$\mathrm{d}_{\mathrm{h}} \quad$ Hydraulic diameter $(\mathrm{m})$

$\mathrm{ft} \quad$ Foot $(=0.3048 \mathrm{~m})$

gallon $3.7854 \times 10^{-3} \mathrm{~m}^{3}$

gpm Gallons/min

$\mathrm{Gr}_{\mathrm{L}} \quad$ Grashof number based on length scale $\mathrm{L}$

$\mathrm{h} \quad$ Convective heat transfer coefficient in Inch $(=0.0254 \mathrm{~m})$

k Thermal conductivity 


$\begin{array}{ll}\mathrm{K} & \text { Absolute temperature }\left(=273.15+{ }^{\circ} \mathrm{C}\right) \\ \mathrm{L} & \text { Length }(\mathrm{m}) \text { or liter } \\ \mathrm{m} & \text { Meter or coefficient } \\ \mathrm{Nu} & \text { Nusselt number }(=\mathrm{hd} / \mathrm{h} / \mathrm{k}) \\ \mathrm{Pr} & \text { Prandtl number } \\ \mathrm{q},, & \text { Volumetric heat source } \\ \mathrm{q}, & \text { Wall heat flux } \\ \mathrm{r} & \text { Local radius } \\ \mathrm{R} & \text { Energy residual }(\mathrm{W}) \text { or Radius } \\ \mathrm{Re} & \text { Reynolds number }(\mathrm{d} \rho \mathrm{u} / \mu) \\ \mathrm{s} \text { or sec } & \text { Second } \\ \mathrm{ss} & \text { Stainless steel } \\ \mathrm{t} & \text { Time }(\mathrm{second}) \text { or degree Centigrade } \\ T_{\infty} & \text { Ambient temperature } \\ \mathrm{U} & \text { Velocity } \\ \mathrm{V}_{\mathrm{b}} & \text { Column bed volume containing heat source } \\ \mathrm{W} & \text { Watts }(\mathrm{J} / \mathrm{sec}) \\ \mathrm{X}, \mathrm{y} & \text { The coordinate system for the two-dimensional } \\ & \text { domain as shown Fig. 1 } \\ \rho & \text { Density } \\ \mu & \text { Dynamic viscosity } \\ \varepsilon & \text { Porosity } \\ \theta & \text { Nondimensional temperature } \\ & \end{array}$

$\begin{array}{ll}\text { Subscript } \\ \text { b } & \text { Column bed } \\ \text { eff } & \text { Effective } \\ \text { f } & \text { Fluid } \\ \text { P } & \text { CST particle } \\ \text { s } & \text { Column surface } \\ \text { w } & \text { Wall }\end{array}$

\section{REFERENCES}

Berninger, J., Whitley, R. D., Zhang, X. and Wang, N.-H. L., 1991. "A Versatile Model for Simulation of Reaction and Nonequilibrium Dynamics in Multicomponent Fixed-Bed Adsorption Processes," Comput. Chem. Eng., vol. 15 (11), pp. 749-768.

Cherry, B. R., Nyman, M., and Alam, T. M., 2004, "Investigation of Cation Environment and Framework Changes in Silicotitanate Exchange Materials Using SolidState 23Na, 29Si, and 133Cs MAS NMR", J. of Solid State Chemistry, vol. 177, pp. 2079-2093.

C. M. Cole, 2007, “CSTF Corrosion Control Program: Program Description Document”, WSRC-TR-2003-00327, Rev. 4, December.

Dittus, F. W. and Boelter, L. M. E., 1930, Engineering Publication vol. 2, pp. 443, University of California.

Duff, M. C., Hunter, D. B., Hobbs, D. T., Fink, S. D., Dai, Z., and Bradley, J. P., 2004, "Mechanisms of Strontium and Uranium Removal from High-Level Radioactive Waste
Simulant Solutions by the Sorbent Monosodium Titanate", Environ. Sci. Technology, vol. 38, pp. 5201-5207.

Fluent $^{T M}$, Ansys, Inc., 2008

Huff, T., Rio-Armstrong, M., Edwards, R., and Herman, D., 2011, "Small Column Ion Exchange Design and Safety Strategy", WM2011 Conference, Paper\# 11325, February 27 - March 3, Phoenix, AZ.

King, W. D., Smith, F. G., Lee, S. Y., McCabe, D. J., and Punch, T., 2007, "Comparisons of RF and CST Media for Cesium Removal by In-Tank Column Processing", $15^{\text {th }}$ Symposium on Separation Science and Technology, Gatlinburg, TN, October.

Krupiczka, R., 1967, "Analysis of Thermal Conductivity in Granular Materials", International Chemical Engineering, vol. 7, No. 1, pp. 122-144.

Lee, S. Y. Lee, 2007, "Heat Transfer Analysis for Fixed CST and RF columns, Savannah River National Laboratory, WSRC-STI-2007-00345, October.

Lee, S. Y., Hensel, S. J., and De Bock, C., 2011, “Thermal Performance Analysis of Geologic High-level Radioactive Waste Packages", ASME J. of Pressure Vessel Technology, vol. 133, pp. 061601-1, December.

Lee, S. Y. and Smith, F. G., 2009, "Thermal Analysis for Intank Ion-Exchange Column Process," ANS Transactions, vol. 100, pp. 785-788.

Miller, J. E. and Brown, N. E., 1997, "Development and Properties of Crystalline Silicotitanate (CST) Ion Exchangers for Radioactive Waste Applications", SAND970771, UC-721, UC-510, Sandia national Laboratories, April.

Smith, F. G., Lee, S. Y. Lee, King, W. D., McCabe, D. J., 2008, "Comparisons of Crystalline Silicotitanate and Resorcinol Formaldehyde Media for Cesium Removal by In-tank Column Processing”, Separation Science and Technology, vol. 43, pp. 2929.

Spencer, B. B., Wang, H., Anderson, K. K., 2000, "Thermal Conductivity of IONSIVIE-911TM Crystalline Silicotitanate and Savannah River Waste Simulant Solutions",ORNL/TM-2000/285, Oak Ridge National Laboratory, TN.

Warner, C. Y. and Arpaci, V. S., 1968, “An Experimental Investigation of Turbulent Natural Convection in Air at Low Pressure along a Vertical Heated Flat Plate", International Journal of Heat and Mass Transfer, vol. 11, pp. 397-406. 